\title{
Penerapan Model Spiral Dalam Pengembangan Sistem Informasi Penjadwalan Produksi Berbasis Website (Studi Kasus: PT . Dinar Makmur Cikarang)
}

\author{
Sri Wahyuni ', Nur Cahyani \\ 'Teknik Informatika, STMIK Cikarang, Jl. Kapten Sumantri No 16 Cikarang, Bekasi 17530 \\ 2Nur Cahyani, STMIK Cikarang, Jl. Kapten Sumantri No ${ }_{16}$ Cikarang, Bekasi 17530
}

\begin{abstract}
INFORMASI ARTIKEL
A B S T R A K

Sejarah Artikel:

Diterima Redaksi : 00 Februari 00

Revisi Akhir : 00 Maret 00

Diterbitkan Online : 00 April 00

Perkembangan era industri $\mathbf{4 . 0}$ menuntut setiap instansi agar bisa memanfaatkan perkembangan teknologi dalam segala bidang. Salah satunya adalah pemanfaatan web pada proses bisnis. PT Dinar Makmur Cikarang merupakan salah satu perusahaan yang menghasilkan barang jenis styroform. Dalam penjadwalan produksi masih dilakukan menggunakan cara manual yang memerlukan waktu lama dalam

Kata Kunci : pengerjaannya. Selain itu pada pendistribusian jadwal yang sudah jadi terhadap pihak-pihak terkait. Dalam penelitian ini akan dikembangkan sistem informasi penjadwalan berbasis web menggunakan metode spiral. Berbasis web bertujuan agar mudah diakses dari beberapa tempat yang berbeda. Menggunakan model spiral dikarenakan pengembangan sistem menggunakan model ini mudah dikembangkan dan memerlukan waktu lebih singkat dibanding model lain. Sistem diuji coba dengan black box testing dan melaksankan Forum Group Discussion dengan dihadiri para pihak terkait dengan penjadwalan proses produksi. Dari FGD yang dilakukan dapat disisimpulkan bahwa sistem yang dihasilkan dapat diterima. Dapat diartikan bahwa sistem ini sesuai dengan kebutuhan yang ada di bagian penjadwalan produksi PT Dinar Makmur Cikarang.
\end{abstract}

\section{PENDAHUluan}

Penggunaan teknologi informasi dalam menunjang sistem informasi membawa pengaruh terhadap hampir semua aspek dalam pengelolaan bisnis. Penerapan teknologi sistem informasi dalam perusahaan, tidak dimanfaatkan secara maksimal oleh individu pemakai teknologi sistem informasi. Hal ini menyebabkan kurangnya manfaat yang diberikan oleh teknologi sistem informasi tersebut khusunya dalam meningkatkan kinerja individual.

PT. Dinar Makmur Cikarang merupakan salah satu perusahaan yang memproduksi barang jenis styrofoam. dalam proses penjadwalan produksi saat ini dilakukan dengan cara menuliskan di papan produksi (whiteboard) kemudian disalin ke formulir jadwal produksi dan berikutnya akan diserahkan ke bagian terkait.

Berdasar uraian permasalahan di atas, maka penelitian ini akan menjawab pertanyaan "Bagaimana mengembangan sebuah sistem penjadwalan produksi berbasis web dengan menggunakan model spiral dalam pengembangannya?"

\section{LANDASAN TEORI}

\subsection{Sistem Informasi}

Sutabri (2005) mendefiniskan sisitem informasi adalah suatu sistem didalam suatu organisai yang mempertemukan kebutuhan pengolahan transaksi harian yang mendukung fungsi operasi organisasi yang bersifat manajerial dengan kegiatan strategi dari suatu organisasi untuk dapat menyediakan kepada pihak luar tertentu dengan laporan-laporan yang diperlukan.

\subsection{Penjadwalan Produksi}

Menurut Nasution (2003), Penjadwalan produksi dapat didefinisikan sebagai proses pengalokasian sumber daya dan mesin yang ada untuk menyelesaikan semua pekerjaan dengan mempertimbangkan batasanbatasan yang ada. Pada saat merencanakan suatu jadwal produksi, ketersediaan sumber daya yang dimiliki harus dipertimbangkan dengan baik

\subsection{Model Sprial}

Spiral Model Merupakan penggabungan ide pengembangan berulang (Prototyping) dengan aspek sistematis terkendali model air terjun (Waterfall). Model spiral juga secara eksplisit meliputi manajemen resiko dalam pengembangan perangkat lunak. Mengidentifikasi resiko utama, baik teknis maupun manajerial, dan menentukan bagaimana untuk mengurangi resiko membantu menjaga proses pengembangan perangkat lunak dibawah control. 


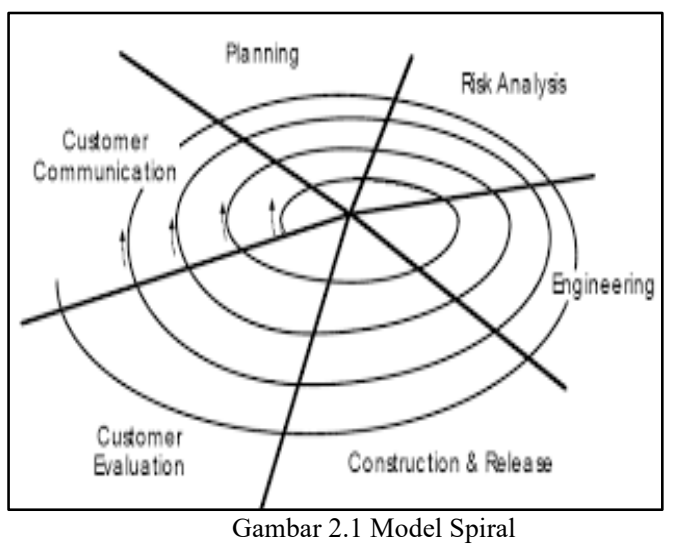

Spiral Model dibagi menjadi beberapa framework aktivitas yang disebut dengan task regions. Kebanyakan aktivitas-aktivitas tersebut dibagi antara 3 sampai 6 aktivitas.

Berikut adalah aktivitas-aktivitas yang dilakukan dalam spiral model :

1. Customer Communication

Aktivitas yang dibutuhkan untuk membangun komunikasi yang efektif antara developer dengan user atau cutomer terutama mengenai kebutuhan dari customer.

\section{Planning}

Aktivitas perencanaan ini dibutuhkan untuk menentukan sumberdaya, perkiraan waktu pengerjaan, dan informasi lainnya yang dibutuhkan untuk pengembangan software.

3. Analysis Risk

Aktivitas analisis resiko ini dijalankan untuk menganalisis baik resiko secara teknikal maupun secara managerial. Tahap inilah yang mungkin tidak ada pada model proses yang juga menggunakan metode iterasi, tetapi hanya dilakukan pada Spiral Model

\section{Engineering}

Aktivitas yang dibutuhkan untuk membangun 1 atau lebih representasi dari aplikasi secara teknikal

\section{Construction \& Release}

Aktivitas yang dibutuhkan untuk develop software, testing, instalasi dan penyediaan user atau customer support seperti training penggunaan software serta dokumentasi seperti buku manual penggunaan software.

\section{Customer Evaluation}

Aktivitas yang dibutuhkan untuk mendapatkan feedback dari user atau customer berdasarkan evaluasi mereka selama representasi software pada tahap engineering maupun pada implementasi selama instalasi software pada tahap conctruction and release

\subsection{Website}

Website dapat diartikan sebagai kumpulan halaman yang berisi informasi data digital baik berupa teks, gambar, animasi, suara dan video atau gabungan dari semuanya yang disediakan melalui jalur koneksi internet. Sehingga dapat diakses dan dilihat oleh semua orang diseluruh dunia. Halaman website dibuat menggunakan bahasa standar yaitu HTML. Skrip HTML ini akan diterjemahkan oleh web browser sehingga dapat ditampilkan dalam bentuk informasi yang dapat dibaca oleh semua orang. (Rohi Abdulloh,2018:1)

\subsection{Kerangka Berpikir}

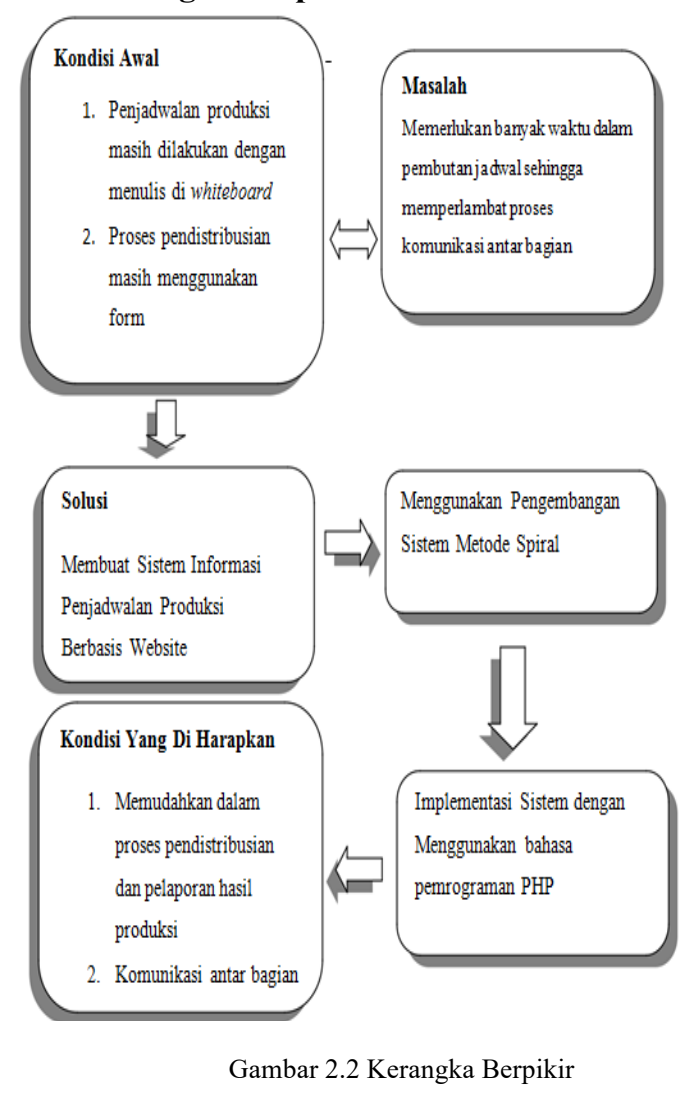

\section{METODOLOGI}

\subsection{Metode Pengumpulan data}

\subsubsection{Observasi}

Dilaksanakan pengamatan langsung dan mendapatkan dokumen-dokumen terkait dan sisem berjalan terkait dengan penjadwalan produksi. Dokumen tersebut adalah jadwal dan pengumuman jadwal.

3.1.2 Wawancara

Dilakukan wawancara untuk mengetahui dengan pasti kebutuhan fungsional dan non fungsional dalam sistem penjadwalan.

3.1.3 Kepustakaan

Penelitian Jurnal, Stikom Surabaya [Dedy Armada Wirtatama, 2016]

Pada penelitian ini merancang aplikasi penjadwalan produksi dengan menggunakan metode Waterfall. Hasil dari penelitian ini adalah aplikasi yang dibuat dapat membantu pihak perusahaan dalam memilih metode terbaik yang digunakan untuk penjadwalan produksi 


\subsection{Metode Pengembangan Sistem}

Menggunakan metode pengembangan spiral yang merupakan penggabungan dari metode waterfall dan prototyping. Pemilihan metode ini dianggap karena metode ini menggunakan waktu lebih singkat dalam pengembangan sistem

\section{PEMBAHASAN DAN HASIL PENELITIAN}

Sistem yang diusulkan dirancang menggunakan metode spiral dengan tahapan sebagai berikut :

\subsubsection{Customer Communication \\ ( Komunikasi Pelanggan )}

Penulis melakukan wawancara dengan pelanggan untuk mendapatkan semua informasi terkait proses yang sedang berjalan diperusahaan. Proses tersebut digambarkan melalui diagram use case dan diagram Activity

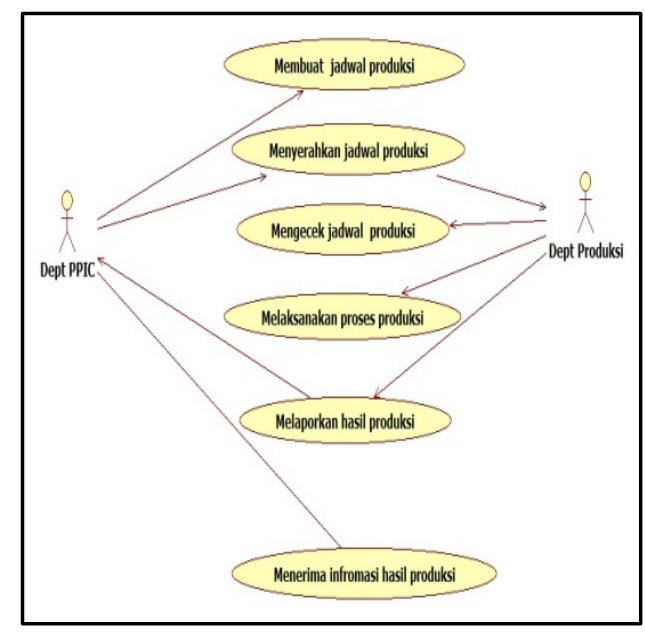

Gambar 4.1 Use Case Sistem Berjalan

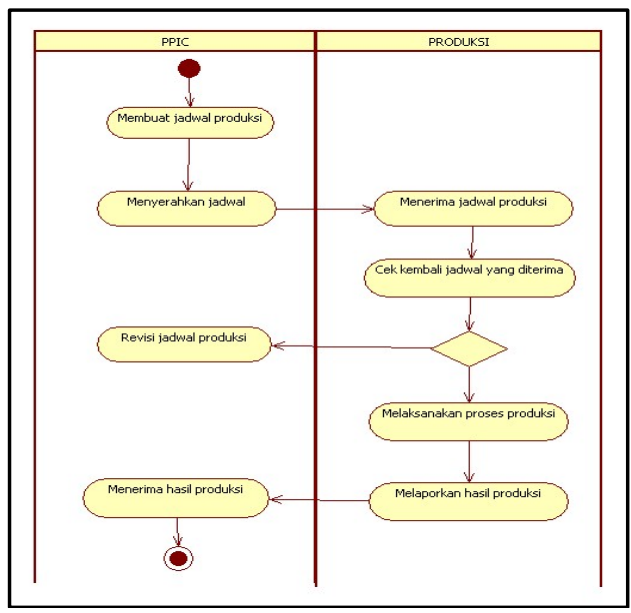

Gambar 4.2Activity Diagram Sistem Berjalan

\subsubsection{Engeneering ( Perencanaan )}

Pada tahapan ini penulis merencanakan kebutuhan sistem agar aplikasi dapat berjalan dengan baik maka diperlukan software dan hardware untuk analisa kebutuhan sistemnya

\section{Spesifikasi Hardware}

Hardware minimum yang diperlukan server untuk pembuatan aplikasi adalah sebagai berikut :

a) Processor Intel (R) Core (TM) i5-3340M CPU (a) $2.70 \mathrm{GHz} 270 \mathrm{GHz}$.

b) RAM minimal 4GB

c) Harddisk $500 \mathrm{~GB}$

d) Mouse

e) Keyboard

\section{Spesifikasi Software}

Software minimum yang diperlukan server adalah sebagai berikut:
a) Windows 7.0
b) PHP
c) MySQL
d) PhpMyAdmin
e) Sublime Text atau Notepad++
f) Browser : Mozila Firefox, Google Chrome

\subsubsection{Analysis Risk (Analisa Resiko )}

Pada tahapan ini penulis menganalisa kebutuhan fungisonal yang dibutuhkan dalam pembuatan system. Adapun menu-menu yang akan penulis rancang sebagai berikut :

Tabel 4.1 Kebutuhan Fungsional

\begin{tabular}{|l|l|}
\hline Nama Kebutuhan & Deskripsi \\
\hline Login & $\begin{array}{l}\text { Halaman utama untuk } \\
\text { Mengakses sistem }\end{array}$ \\
\hline Menu Beranda & $\begin{array}{l}\text { Halaman yang muncul } \\
\text { setelah melakukan login } \\
\text { berhasil }\end{array}$ \\
\hline Menu Data Mesin & $\begin{array}{l}\text { Untuk melihat data } \\
\text { nomer mesin }\end{array}$ \\
\hline Menu Part Number & $\begin{array}{l}\text { Untuk melihat data } \\
\text { nama produk }\end{array}$ \\
\hline $\begin{array}{l}\text { Menu Data } \\
\text { Customer }\end{array}$ & $\begin{array}{l}\text { Untuk melihat data } \\
\text { nama pelanggan }\end{array}$ \\
\hline $\begin{array}{l}\text { Menu Data Jadwal } \\
\text { produksi }\end{array}$ & $\begin{array}{l}\text { Menu untuk melihat } \\
\text { data jadwal produksi }\end{array}$ \\
\hline $\begin{array}{l}\text { Menu Status } \\
\text { Produksi }\end{array}$ & $\begin{array}{l}\text { Untuk melihat kategori status } \\
\text { produksi }\end{array}$ \\
\hline $\begin{array}{l}\text { Menu Monitoring } \\
\text { Jadwal Produksi }\end{array}$ & $\begin{array}{l}\text { Untuk mengontrol proses } \\
\text { produksi }\end{array}$ \\
\hline
\end{tabular}

\subsubsection{Engeneering ( Perancangan )}

Penulis akan mengusulkan rancangan sistem tersebut dengan menggunakan metode pendekatan sistem berorientasi objek melalui sebuah diagram UML. Diagram Use case sistem informasi penjadwalan produksi yang diusulkan peneliti dalam pendistribusian jadwal produksi di PT. Dinar Makmur Cikarang adalah sebagai berikut : 
1. Use Case Diagram Sistem yang diusulkan Berikut adalah rancangan yang diusulkan oleh penulis :

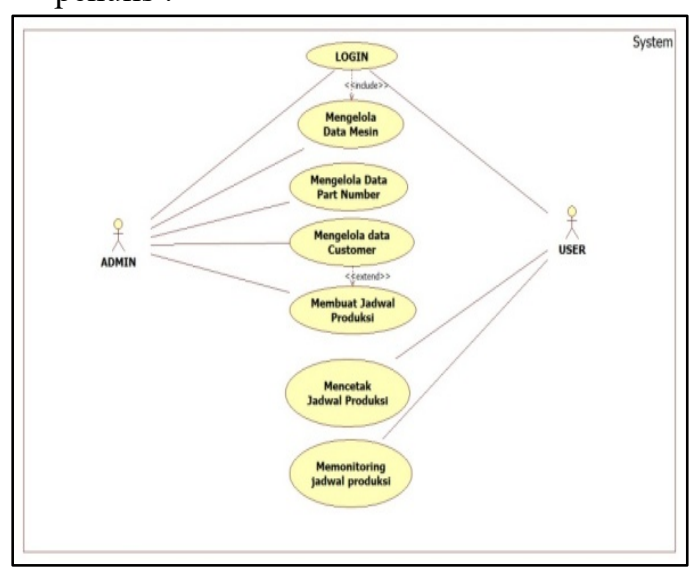

Gambar 4.3 Use Case Sistem Usulan

2. Rancangan Menu Utama

a) Rancangan Menu Utama Admin

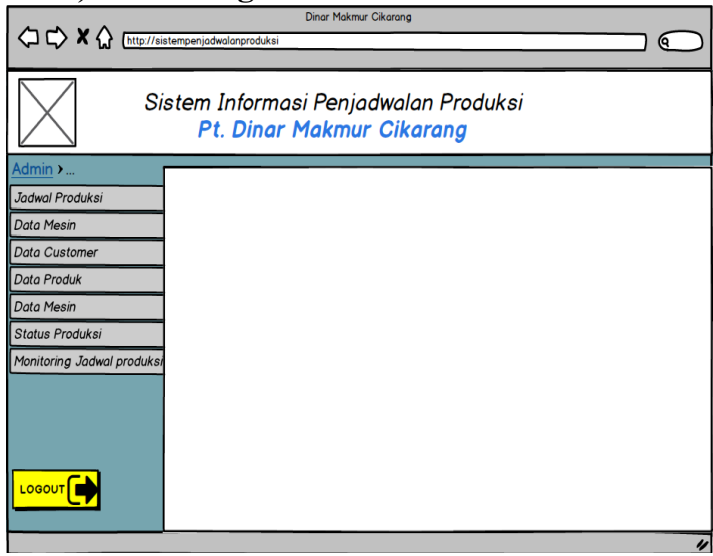

Gambar 4.4 Menu Utama Admin

b) Rancangan Menu Utama User

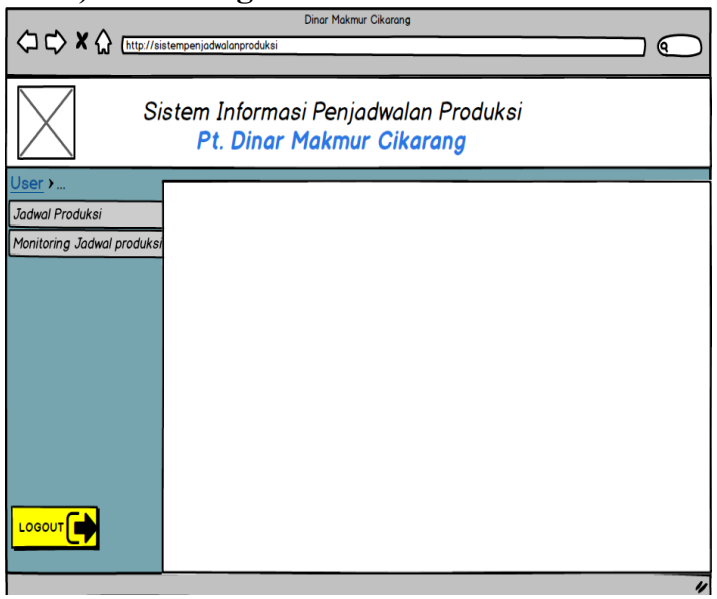

Gambar 4.5 Menu Utama User c) Rancangan Menu Jadwal Produksi

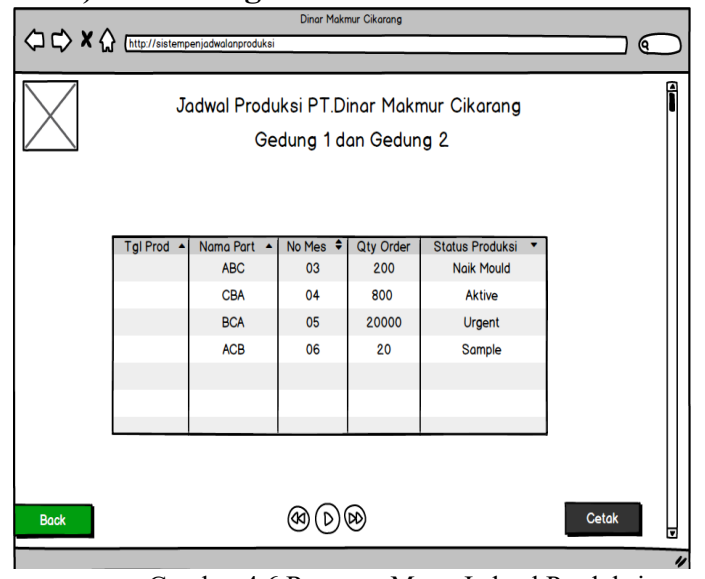

Gambar 4.6 Rancang Menu Jadwal Produksi

d) Rancangan Menu Monitoring Jadwal Produksi

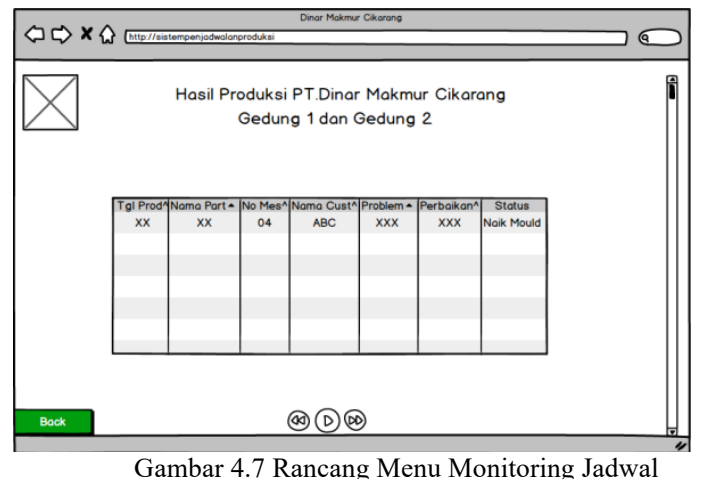

\subsubsection{Construction and Release}

a) Tampilan Menu Utama Admin

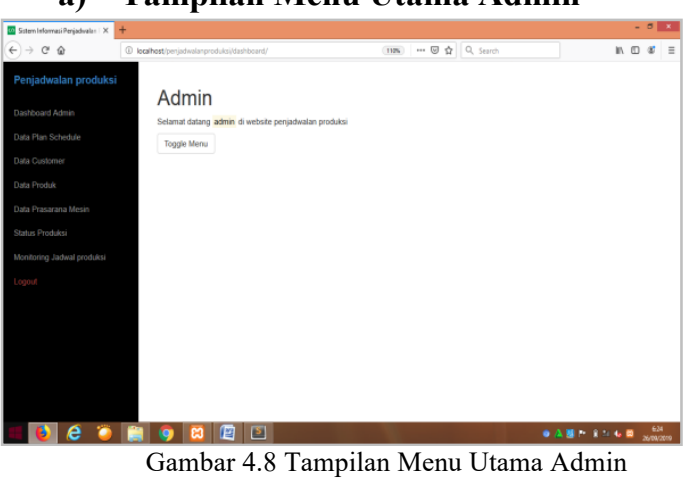

b) Tampilan Menu Utama User

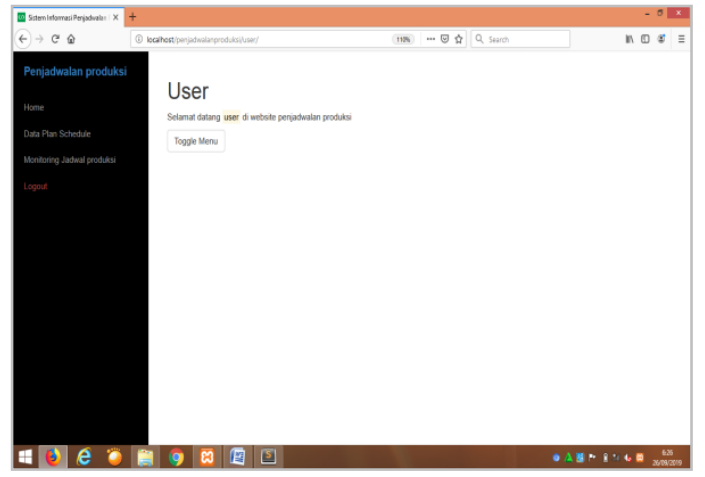

Gambar 4.9Tampilan Menu Utama user 


\section{c) Tampilan Menu Jadwal Produksi}

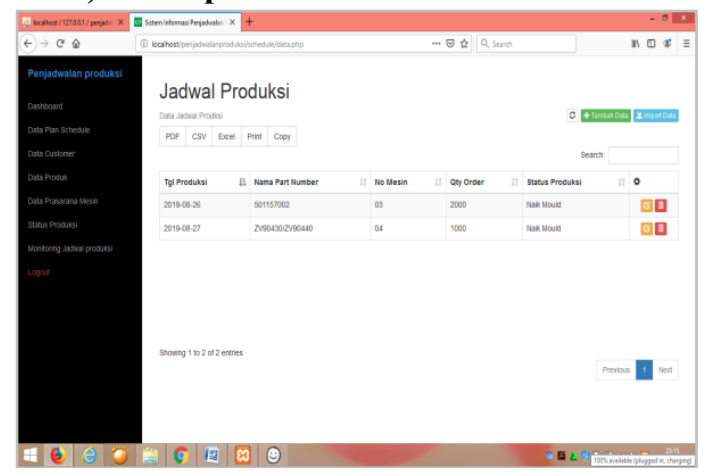

Gambar 4.10 Tampilan Menu Jadwal Produksi

d) Tampilan Menu Monitoring Jadwal Produksi

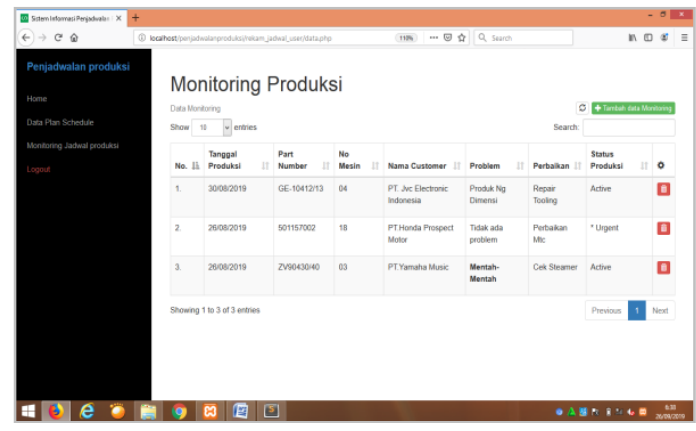

Gambar 4.11 Tampilan Menu Monitoring Jadwal

\subsubsection{Customer Evaluation}

1. Verifikasi Kinerja Sistem

Tahap ini adalah akhir dari metode spiral, dimana penulis melakukan pengujian apakah sistem yang dibuat sudah bekerja dengan baik atau belum. Pengujian perangkat lunak ini menggunakan black box testing, yaitu pengujian yang dilakukan dengan hanya mengamati hasil eksekusi melalui data uji dan memeriksa fungsional dari perangkat lunak.

Table 4.2 Hasil Uji Sistem

\begin{tabular}{|l|l|l|l|l|}
\hline NO & $\begin{array}{l}\text { Kelas } \\
\text { Uji }\end{array}$ & $\begin{array}{l}\text { Skenar } \\
\text { io Uji }\end{array}$ & Output & Kesimpulan \\
\hline 1 & $\begin{array}{l}\text { Menu } \\
\text { Dashb } \\
\text { oard }\end{array}$ & $\begin{array}{l}\text { Klik } \\
\text { Menu } \\
\text { Dashb } \\
\text { oard }\end{array}$ & $\begin{array}{l}\text { Masuk ke } \\
\text { Menu } \\
\text { Dashboard }\end{array}$ & $\begin{array}{l}{[\sqrt{ }] \text { Berhasil }} \\
\text { Berhasil }\end{array}$ \\
\hline 2 & $\begin{array}{l}\text { Tomb } \\
\text { ol } \\
\text { Data } \\
\text { Custo } \\
\text { mer }\end{array}$ & $\begin{array}{l}\text { Klik } \\
\text { Tombo } \\
1\end{array}$ & $\begin{array}{l}\text { Menampil } \\
\text { kan Form } \\
\text { mer } \\
\text { Data } \\
\text { Customer }\end{array}$ & $\begin{array}{l}{[\sqrt{ }] \text { Berhasil }} \\
{[\text { B Tidak }} \\
\text { Berhasil }\end{array}$ \\
& $\begin{array}{l}\text { Klik } \\
\text { Menu } \\
\text { Tamba } \\
\text { h Data } \\
\text { Custo } \\
\text { menambah } \\
\text { data } \\
\text { Customer }\end{array}$ & \\
\hline
\end{tabular}

\begin{tabular}{|c|c|c|c|c|}
\hline 3 & $\begin{array}{l}\text { Tomb } \\
\text { ol } \\
\text { Data } \\
\text { Prasar } \\
\text { ana } \\
\text { Mesin }\end{array}$ & $\begin{array}{l}- \text { Klik } \\
\text { Tombo } \\
1 \\
\text { Prasara } \\
\text { na } \\
\text { Mesin } \\
\text {-Klik } \\
\text { Menu } \\
\text { Tamba } \\
\text { h Data } \\
\text { Mesin }\end{array}$ & $\begin{array}{l}\text { - } \\
\text { Menampil } \\
\text { kan Form } \\
\text { Prasarana } \\
\text { Mesin } \\
-\quad \text { Admin } \\
\text { menambah } \\
\text { data } \\
\text { prasarana } \\
\text { mesin }\end{array}$ & $\begin{array}{l}{[\sqrt{ }] \text { Berhasil }} \\
{[\quad] \text { Tidak }} \\
\text { Berhasil }\end{array}$ \\
\hline 4 & $\begin{array}{l}\text { Tomb } \\
\text { ol } \\
\text { Data } \\
\text { Part } \\
\text { Numb } \\
\text { er }\end{array}$ & $\begin{array}{l}- \text {-Klik } \\
\text { Tombo } \\
\text { 1 Input } \\
\text { Part } \\
\text { Numbe } \\
\text { r } \\
\text {-Klik } \\
\text { Menu } \\
\text { Tamba } \\
\text { h Data } \\
\text { Part }\end{array}$ & $\begin{array}{l}- \\
\text { Menampil } \\
\text { kan Form } \\
\text { Data Part } \\
\text { Number } \\
\text {-Admin } \\
\text { menambah } \\
\text { data part } \\
\text { number }\end{array}$ & $\begin{array}{l}{[\sqrt{ }] \text { Berhasil }} \\
{[\quad] \text { Tidak }} \\
\text { Berhasil }\end{array}$ \\
\hline 5 & $\begin{array}{l}\text { Tomb } \\
\text { ol } \\
\text { Status } \\
\text { Produ } \\
\text { ksi }\end{array}$ & $\begin{array}{l}\text {-Klik } \\
\text { Menu } \\
\text { Tamba } \\
\text { h } \\
\text { Ketera } \\
\text { ngan }\end{array}$ & $\begin{array}{l}\text { - } \\
\text { Menampil } \\
\text { kan form } \\
\text { status } \\
\text { produksi } \\
\text {-Admin } \\
\text { menambah } \\
\text { data status } \\
\text { produksi }\end{array}$ & $\begin{array}{l}{[\sqrt{ }] \text { Berhasil }} \\
{[\quad] \text { Tidak }} \\
\text { Berhasil }\end{array}$ \\
\hline 6 & $\begin{array}{l}\text { Tomb } \\
\text { ol } \\
\text { Input } \\
\text { Jadwal } \\
\text { Produ } \\
\text { ksi }\end{array}$ & $\begin{array}{l}\text { Klik } \\
\text { Menu } \\
\text { Tamba } \\
\text { h } \\
\text { Jadwal } \\
\text { produk } \\
\text { si }\end{array}$ & $\begin{array}{l}\text { Menampil } \\
\text { kan Form } \\
\text { Jadwal } \\
\text { Produksi } \\
\text {-Admin } \\
\text { menginput } \\
\text { data jadwal } \\
\text { produksi }\end{array}$ & $\begin{array}{l}{[\sqrt{ }] \text { Berhasil }} \\
{[\quad] \text { Tidak }} \\
\text { Berhasil }\end{array}$ \\
\hline 7 & $\begin{array}{l}\text { Tomb } \\
\text { ol } \\
\text { Monit } \\
\text { oring } \\
\text { Jadwal } \\
\text { Produ } \\
\text { ksi }\end{array}$ & $\begin{array}{l}\text { Klik } \\
\text { Menu } \\
\text { Tamba } \\
\text { h Data } \\
\text { Monito } \\
\text { ring }\end{array}$ & $\begin{array}{l}\text { - } \\
\text { Menampil } \\
\text { kan form } \\
\text { monitoring } \\
\text { jadwal } \\
\text { produksi } \\
-\quad \text { Admin } \\
\text { melihat } \\
\text { data } \\
\text { monitoring }\end{array}$ & $\begin{array}{l}{[\sqrt{ }] \text { Berhasil }} \\
{[\quad] \text { Tidak }} \\
\text { Berhasil }\end{array}$ \\
\hline 8 & $\begin{array}{l}\text { Menu } \\
\text { Logou } \\
t\end{array}$ & $\begin{array}{l}\text { Klik } \\
\text { Menu } \\
\text { Logout }\end{array}$ & $\begin{array}{l}\text {-Kembali } \\
\text { ke Menu } \\
\text { Logiin }\end{array}$ & $\begin{array}{l}{[\sqrt{ }] \text { Berhasil }} \\
{[\quad] \text { Tidak }} \\
\text { Berhasil }\end{array}$ \\
\hline
\end{tabular}

\section{Validasi Pengguna Sistem}

Dalam pengujian kelayakan sistem, penulis menggunakan tahapan uji kelayakan dengan dilaksanakan FGD. Kuisoner merupakan daftar pertanyaan yang diajukan kepada responden untuk 
mencari jawaban dari permasalahan yang diteliti. Berikut hasil pengujian nya

Tabel 4.3 Hasil Perhitungan Respon FGD

\begin{tabular}{|c|c|c|c|c|c|}
\hline No & Pertanyaan & SS & $\mathbf{S}$ & TS & STS \\
\hline 1 & $\begin{array}{l}\text { Menu-menu } \\
\text { yang ada pada } \\
\text { aplikasi ini } \\
\text { mudah } \\
\text { dipahami }\end{array}$ & $75 \%$ & $25 \%$ & & \\
\hline 2 & $\begin{array}{l}\text { Menu-menu } \\
\text { yang ada pada } \\
\text { aplikasi ini } \\
\text { mudah } \\
\text { digunakan }\end{array}$ & $75 \%$ & $25 \%$ & & \\
\hline 3 & $\begin{array}{l}\text { Komponen } \\
\text { tombol pada } \\
\text { aplikasi ini } \\
\text { sudah sesuai } \\
\text { dengan } \\
\text { fungsinya }\end{array}$ & $50 \%$ & $50 \%$ & & \\
\hline 4 & $\begin{array}{l}\text { Apakah Menu } \\
\text { Jadwal } \\
\text { Produksi } \\
\text { button import } \\
\text { data sudah } \\
\text { sesuai dengan } \\
\text { fungsinya }\end{array}$ & & $\begin{array}{l}100 \\
\%\end{array}$ & & \\
\hline 5 & $\begin{array}{l}\text { Apakah Menu } \\
\text { cetak jadwal } \\
\text { sudah sesuai } \\
\text { dengan } \\
\text { kebutuhan dan } \\
\text { fungsinya }\end{array}$ & $50 \%$ & $50 \%$ & & \\
\hline 6 & $\begin{array}{l}\text { Menu } \\
\text { monitoring } \\
\text { jadwal sudah } \\
\text { sesuai dengan } \\
\text { kebutuhan dan } \\
\text { fungsinya }\end{array}$ & $50 \%$ & $25 \%$ & $25 \%$ & \\
\hline 7 & $\begin{array}{l}\text { Aplikasi ini } \\
\text { dapat menjadi } \\
\text { media } \\
\text { pendistribusia } \\
\text { n jadwal }\end{array}$ & $75 \%$ & $25 \%$ & & \\
\hline 8 & $\begin{array}{l}\text { Aplikasi ini } \\
\text { dapat menjadi } \\
\text { media } \\
\text { monitoring } \\
\text { kontrol proses } \\
\text { produksi }\end{array}$ & $50 \%$ & $50 \%$ & & \\
\hline
\end{tabular}

Dari pengujian yang telah dilakukan, berdasarkan pilihan kategori jawaban dari kuesioner yang telah disebarkan kepada user, Maka dapat disimpulkan bahwa bahwa secara fungsional sistem informasi aplikasi tersebut dapat menghasilkan output yang diharapkan, Sehingga layak untuk diterapkan sebagai sistem informasi penjadwalan produksi yang digunakan sebagai media pendistribusian jadwal produksi dan penyampaian informasi mengenai proses produksi.

\section{KESIMPULAN}

Dari pengembangan sistem informasi penjadwalan produksi berbasis website yang telah dilakukan, maka penulis dapat menyimpulkan bahwa sistem informasi ini dapat menyelesaikan masalahmasalah sebagai berikut:

1. Dengan adanya sistem penjadwalan produksi berbasis website dapat mempercepat kegiatan dalam proses pendistribusian jadwal produksi

2. Memudahkan proses penyampaian informasi antar bagian PPIC dengan produksi pada PT.Dinar Makmur Cikarang

\section{DAFTAR PUSTAKA}

[1] Anggraeni, Elisabet Yunaeti, dan Rita Irviani. Pengantar Sistem Informasi, CV.Andi Offset, 2016

[2] Enterprise,Jubile. MySQL untuk Pemula, Elex Media Komputindo, Desember 2014

[3] Hendini, Ade. Pemodelan UML Sistem Informasi Monitoring Penjualan dan Stok Barang, Jurnal Khatulistiwa Informatika, Vol. IV, No.2. Desember 2016

[4] Muslihudin, Muhamad, dan Oktafianto. Analisis dan Perancangan Sistem Informasi Menggunakan Model Terstruktur dan UML, CV.Andi Offset, 2016

[5] Sanjaya, Ginanjar Tegar, Budhi Sumboro.Rancang Bangun Aplikasi Penjadwalan kuliah Stmik AUB Surakarta Berbasis Web, Jurnal Ilmiah Go Infotech, ISSN 1693-590X, Vol. 21 No. 1, Juni 2015

[6] Sattar. Buku Ajar Pengantar Bisnis, Deepublish, Agustus 2017

[7] Sulistiono, Heru. Coding Mudah dengan CodeIgniter, Jquery, Bootstrap, danData table, Elex Media Komputindo, 2018

[8] Suprianto, Andi, Asri Amaliza Fathia Matsea.Rancang Bangun Aplikasi Pendaftaran Pasien Online dan Pemeriksaan Dokter di Klinik Pengobatan Berbasi Web, Jurnal Rekayasa Informasi, ISSN 2252-7354, Vol. 7 No. 1, April 2018

[9] Suprianto, Dodit, Membuat Aplikasi Desktop Menggunakan MySQL \& VB.NET Secara Profesional, Media Kita, 2010

[10] Sutabri, Tata. Konsep Sistem Infromasi, CV.Andi Offset, 2012

[12] Wiratama, Dedy Armada, Antok Supriyanto, Januar Wibowo. Rancang Bangun Aplikasi Penjadwalan Produksi Pada PT.Bina Megah Indowood, JSIKA, ISSN 2338-137X, Vol. 5, No.1. 2016

[13] Yurindra. Software Engeneering, Deepublish, April 2017 